\title{
Influence of Phenolic Compounds on Antioxidant and Anticorrosion Activities of Ammi visnaga Extracts Obtained Ultrasonically in Three Solvent Systems
}

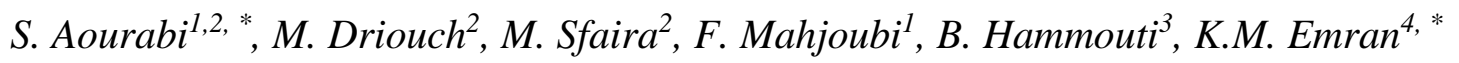 \\ ${ }^{1}$ Laboratoire de Génie des Matériaux et Environnement, Faculté des Sciences, Université Sidi \\ Mohamed Ben Abdellah (USMBA), B.P. 1796-30000, Fès-Atlas, Morocco. \\ ${ }^{2}$ Laboratoired'Ingénierie des Matériaux, de Modélisation et d'Environnement. Université Sidi \\ Mohamed Ben Abdellah (USMBA), Faculté des Sciences B.P. 1796-30000, Fès-Atlas, Morocco. \\ ${ }^{3}$ Laboratoirede la chimie appliquée et d'environnement, Faculté des sciences, Université Mohammed \\ Premier, BP 4808 Oujda, Morocco. \\ ${ }^{4}$ Department of Chemistry, College of Science, Taibah University, Al-Madinah Al-Monawarah, PO \\ Box 4050, Saudi Arabia \\ *E-mail: kabdalsamad@taibahu.edu.sa \& sarra.aourabi1@ gmail.com
}

doi: $10.20964 / 2019.07 .02$

Received: 15 February 2019/ Accepted: 23 April 2019 / Published: 10 June 2019

The purpose of this research was to study the correlation between phenolic compounds and antioxidant as well as anticorrosive activities of different extracts of Ammi visnaga. The antioxidant capacity was evaluated by 2,2-diphenyl-1-picrylhydrazyl ( $\left.\mathrm{DPPH}^{*}\right)$. The phenolic compounds, namely, total phenol content (TPC), total flavonoids content (TFC), and condensed tannins (CT), were determined by FolinCiocalteu, Quettier-Deleu, and Broadhurst methods, respectively. In addition, the inhibiting effect of different extracts of $A$. visnaga on mild steel in $1 \mathrm{M} \mathrm{HCl}$ solution was investigated by potentiodynamic polarization (PP) and electrochemical impedance spectroscopy (EIS). The obtained results revealed that the mixed aqueous extract had a high level of phenolic compounds when compared with pure solvents. Hydroalcoholic extract had the highest radical trapping capacity $\left(I C_{50}=1.7 \mathrm{mg} / \mathrm{mL}\right)$ compared with standard butylated hydroxytoluene (BHT) $\left(I C_{50}=0.2 \mathrm{mg} / \mathrm{mL}\right)$. The PP tests showed that the extracts act as mixed inhibitors, whereas EIS measurements indicated that action inhibition of mild steel can be explained by the adsorption of active compounds at the metal surface. The trends between condensed tannins and antioxidant activity, as well as the inhibition efficiency derived from Tafel plots and EIS, were revealed, respectively.

Keywords: Ammi visnaga extract; TPC; TFC; condensed tannins; antioxidant activity; corrosion inhibition. 
(C) 2019 The Authors. Published by ESG (www.electrochemsci.org). This article is an open access article distributed under the terms and conditions of the Creative Commons Attribution license (http://creativecommons.org/licenses/by/4.0/). 